\title{
Lack of Association Between ACE Indel Polymorphismand Cardiorespiratory Fitness in Physically Active and Sedentary Young Women
}

\author{
Rozangela Verlengia ${ }^{1, *}$; Ana C. Rebelo ${ }^{2}$; Alex H. Crisp ${ }^{1}$; Vandeni C. Kunz ${ }^{3}$; Marco A. dos \\ Santos Carneiro Cordeiro ; Mario H. Hirata ${ }^{4}$; Rosario D. Crespo Hirata ${ }^{4}$; Ester Silva ${ }^{5}$ \\ ${ }^{1}$ College of Health Sciences, Methodist University of Piracicaba, Piracicaba, Brazil \\ ${ }^{2}$ Department of Morphology, Federal University of Goias, Goiania, Brazil \\ ${ }^{3}$ Adventist University of Sao Paulo, Engenheiro Coellho, Sao Paulo, Brazil \\ ${ }_{4}^{4}$ School of Pharmaceutical Sciences, University of Sao Paulo, Sao Paulo, Brazil \\ 5 Department of Physiotherapy, Federal University of Sao Carlos, Sao Carlos, Brazi \\ ${ }^{*}$ Corresponding author: Rozangela Verlengia, College of Health Sciences, Methodist University of Piracicaba, Piracicaba, Sao Paulo, Brazil. Tel: $+55-151931241558$, Fax: $+55-151931241659$, \\ E-mail: rverleng@unimep.br
}

Received: July 10, 2013; Accepted: April 4, 2014

\begin{abstract}
Background: Polymorphisms at the angiotensin-converting enzyme gene (ACE), such as the indel [rs1799752] variant in intron 16, have been shown to be associated with aerobic performance of athletes and non-athletes. However, the relationship between ACE indel polymorphism and cardiorespiratory fitness has not been always demonstrated.

Objectives: The relationship between ACE indel polymorphism and cardiorespiratory fitness was investigated in a sample of young Caucasian Brazilian women.

Patients and Methods: This study investigated 117 healthy women (aged 18 to 30 years) who were grouped as physically active (n = 59) or sedentary $(\mathrm{n}=58)$. All subjects performed an incremental exercise test (ramp protocol) on a cycle-ergometer with $20-25 \mathrm{~W} / \mathrm{min}$ increments. Blood samples were obtained for DNA extraction and to analyze metabolic and hormonal profiles. ACE indel polymorphism was determined by polymerase chain reaction (PCR) and fragment size analysis.

Results: The physically active group had higher values of peak oxygen uptake $\left(\mathrm{VO}_{2}\right.$ peak), carbon dioxide output $\left(\mathrm{VCO}_{2}\right)$, ventilation (VE)and power output than the sedentary group $(\mathrm{P}<0.05)$ at the peak of the exercise test. However, heart rate $(\mathrm{HR})$, systolic blood pressure (SBP) and diastolic blood pressure (DBP) did not differ between groups. There was no relationship between ACE indel polymorphism and cardiorespiratory variables during the test in both the physically active and sedentary groups, even when the dominant (DD vs. D1 +2$)$ and recessive (2 vs. DI + DD) models of inheritance were tested.

Conclusions: These results do not support the concept that the genetic variation at the ACE locus contributes to the cardiorespiratory responses at the peak of exercise test in physically active or sedentary healthy women. This indicates that other factors might mediate these responses, including the physical training level of the women.
\end{abstract}

Keywords: Exercise Test; Angiotensin-Converting Enzyme; Polymorphism, Genetic; Motor Activity

\section{Background}

Physical exercise requires the interaction of various physiological mechanisms that enable the cardio-respiratory system to support the increased energy demands of contracting muscles (1). Oxygen uptake $\left(\mathrm{VO}_{2}\right)$ is influenced by the interaction of several variables including environmental, morphophysio logical, and genetic factors $(2,3)$. The most accurate measure of $\mathrm{VO}_{2}$ involves a direct measurement of expired gases during a maximal cardiopulmonary exercise test (CPET). This parameter has been widely used for the measurement of cardiorespiratory per-formance, as a basis for prescribing training intensities, and as a prognostic tool for health status $(4,5)$. Angiotensin-converting enzyme (ACE) is a key enzyme within the renin-angiotensin system (RAS), where the conversion of angiotensin I (ANG I) produces angiotensin 2 (ANG 2), a vasoconstrictor. ACE is also associ- ated with the degradation of other vasodilators, such as bradykinin. The RAS influences circulatory and local systems, including skeletal muscle. These roles of ACE may contribute to the improvement of metabolic efficiency and endurance performance $(6,7)$.

Polymorphisms at the ACE gene, such as the insertion/ deletion (indel) variant of $287 \mathrm{bp}$ in intron 16 (rs1799752), have been shown to be associated with ACE activity variations and with phenotypes of strength/power or endurance performance $(8,9)$. In this context, ACE genotype II is predominant in elite athletes that require high cardiorespiratory capacity, such as rowers $(10,11)$, long distance runners $(12,13)$, long distance swimmers (13), ironman triathletes (14) and climbers $(15,16)$. Individuals carrying genotype II are thus prone to having better cardiorespiratory parameters and consequently better endurance

Copyright (C) 2014, Kowsar Corp.; Published by Kowsar. This is an open-access article distributed under the terms of the Creative Commons Attribution-NonCommercial 4.0 International License (http://creativecommons.org/licenses/by-nc/4.0/) which permits copy and redistribute the material just in noncommercial usages, provided the original work is properly cited. 
Verlengia R et al.

performance. The peak or maximum oxygen uptake $\left(\mathrm{VO}_{2}\right.$ peak or max), a standard measure of cardiorespiratory system and aerobic metabolism; shows great variability in response to physical training and it was estimated that at least 50\% are influenced by genetic factors (17). However, the influence of the ACE indel polymorphism on $\mathrm{VO}_{2}$ peak or max values has not been consistently demonstrated. Hagberg et al. reported that, in postmenopausal women, ACE II genotype carriers presented higher $\mathrm{VO}_{2}$ max values compared with those carrying the $\mathrm{DD}$ genotype $(18,19)$. On the other hand, other studies have failed to establish a positive relationship between the ACE indel variant and maximal aerobic power in young sedentary women (20), sedentary Caucasian and black subjects (21), army recruits (22), and sedentary and endurance-trained women (23).

\section{Objectives}

This study investigated the relationship between ACE indel polymorphisms and cardiorespiratory fitness in a sample of both physically active and sedentary Caucasian women from Brazil.

\section{Patients and Methods}

\subsection{Subjects and Study Design}

The sample size was calculated based on the frequency of the ACE II genotype described in a sample of the European population (18). Assuming a margin of error of $10 \%$ for the estimate with 0.80 of power in the test, and a significance level of 5\%, a minimum number of 118 independent individuals were obtained. All participants completed a health questionnaire and signed an informed consent document after being informed about the research. The present study was approved by the Research Ethics Committee of the Methodist University of Piracicaba (Protocol $n^{\circ} 43 / 06$ ) and is in accordance with the legal requirements of the Declaration of Helsinki.

A group of 117 healthy Caucasian women who were 18 to 30 years of age in the Brazilian cohort were selected and grouped as sedentary $(\mathrm{n}=58)$ and physically active $(n=59)$. The physically active women performed continuous physical activity at least 3 days per week (for at least 6 months) at an intensity of $65-90 \%$ of maximum heart rate with durations of 30-60 minutes in accordance with the American College of Sports Medicine (24). The inclusion criteria for all subjects were: body mass index (BMI) between 19.0 and $24.9 \mathrm{~kg} / \mathrm{m}^{2}$; ovulation confirmed by serum progesterone above $4.0 \mathrm{mg} / \mathrm{mL}$ on the 21st day of the menstrual cycle.

The exclusion criteria included cardiovascular dysfunction (arrhythmia, myocardial ischemia), blood pressure (BP) alterations at rest, depression, gynecological, musculoskeletal or neurological diseases, hyperandrogenism, pregnancy, smoking, and the use of any type of medication that could interfere in the cardiorespiratory system.

\subsection{Physical and Biochemical Assessment}

All subjects underwent a clinical examination and an assessment was performed between the 7th and 10th day of the menstrual cycle, in consideration of the lower hormonal fluctuations during this phase (follicular phase). The exam included the use of a standard 12-lead electrocardiogram (ECG) at rest. Cardiac auscultation, heart rate (HR), and BP were evaluated after 5 minutes of rest in the supine and sitting positions. The BP was measured three times at rest by auscultation of Korotkoff sounds using a mercury-column sphygmomanometer (WanMed, Sao Paulo, SP, Brazil) and stethoscope (Littman, St. Paul, MN, USA).

For biochemical measurements, venous blood samples were drawn after 12 hours of an overnight fast. Serum concentrations of total cholesterol, triglycerides, urea, and creatinine were determined by enzymatic colorimetric assays (BioSystems, Barcelona, Spain). The low-density lipoprotein (LDL) was estimated by Friedewald's formula (25) (since triglycerides values were less than $400 \mathrm{mg} / \mathrm{dL}$ ). All the volunteers were in good health and had biochemical parameters within normal ranges.

\subsection{Evaluation of Cardiorespiratory Fitness}

Experiments were always carried out between 2:00 to 4:00 p.m. to avoid different responses caused by circadian changes. Room temperature was kept at $23^{\circ} \mathrm{C}$ and relative air humidity between $40-60 \%$. Subjects were acquainted with the experimental protocol and instructed to abstain from stimulants and alcoholic beverages (coffee, tea, soft drinks), avoid any exhausting physical activity during the 24 hours preceding the exam, and to ingest a light meal at least 2 hours before the measurements.

CPET was performed on a cycle ergometer with electromagnetic braking (Quinton Corival 400, Seattle, WA, USA) whose seat was adjusted to allow approximately 5 to 10 degrees of knee flexion. The protocol consisted of 1 minute pre-testing while seated in a resting position on the cycle ergometer followed by a 4 minute warm-up period at $4 \mathrm{~W}$. The workload was then increased continuously by 20 to $25 \mathrm{~W} /$ minute until physical exhaustion, i.e. the moment at which the subject could no longer maintain $60 \mathrm{rpm}$ or the occurrence of a limiting symptom or respiratory fatigue. Workload increments were determined for each subject according to the formula proposed by Wasserman et al. (Workload increase $(W)=[$ (height-age) $\times 20]-[150+(6 \times$ body mass $)] / 100(1)$.

During the CPET, ventilatory and metabolic variables, such as the relative oxygen uptake $\left(\mathrm{VO}_{2} \mathrm{~mL} / \mathrm{kg} /\right.$ minute $)$, carbon dioxide output $\left(\mathrm{VCO}_{2}\right)$, and ventilation (VE) were obtained on a breath-by-breath basis using a specific metabolic analyzer (CPX/D MedGraphics Breeze, St. Paul, MN, USA). These variables were subsequently processed and calculated as moving means after every eight respiratory cycles for a better kinetic observation during the exercise testing. The highest value of oxygen consumption achieved during the CPET was considered $\mathrm{VO}_{2}$ peak. 
Verlengia R et al.

The standard criteria of exhaustion were verified by at least three conditions including: A) plateau in oxygen consumption (change $<2 \mathrm{~mL} / \mathrm{kg} /$ minute); B) a respiratory exchange ratio (RER) $\geq 1.1 ; \mathrm{C}) \leq 10$ beats/min of age predicted maximum (220-years of age) and d) rating of perceived exertion (RPE) $\geq 18$ (26).

We also determined HR (Polar, Vantage NV, Finland), systolic blood pressure (SBP), and diastolic blood pressure (DBP), which were determined at the highest values of these variables achieved during the maximal CPET.

\subsection{ACE Indel Polymorphism Analysis}

DNA was isolated from white blood cells EDTA-treated, anti-coagulated blood using a standard protocol as described by Salazar et al. (27) The ACE indel (rs1799752) polymorphism was analyzed by polymerase chain reaction (PCR) and fragment analysis as previously described (28). Sequences of PCR primers were: sense 5'-CTG GAG ACC ACT CCC ATC CTT TCT-3' and anti-sense 5'-GAT GTG GCC ATC ACA TTC AGAT-3'. The PCR assays were carried out in a thermocycler (T-Gradient, Whatman Biometra, Goettingen, Germany) under the following conditions: one cycle at $95^{\circ} \mathrm{C}$ for $5 \mathrm{~min} ; 35$ cycles at $95^{\circ} \mathrm{C}$ for 1 minute, $58^{\circ} \mathrm{C}$ for 1 minute, $72^{\circ} \mathrm{C}$ for 1 minute and one cycle at $72^{\circ} \mathrm{C}$ for 10 minutes. ACE indel fragments were detected by a $1.5 \%$ agarose gel electrophoresis. To avoid a misclassification of ID heterozygotes as DD homozygotes, a second PCR assay was performed in all of the samples initially classified as DD with the insertion-specific primers: sense 5'-CTG GAG ACC ACT CCC ATC CTT TCT-3' and anti-sense 5'-GAT GTG GCC ATC ACA TTC GTC AGA T-3' (29). The PCR conditions were similar as previously stated except for the annealing temperature $\left(64^{\circ} \mathrm{C}\right)$. Only I allele generates a $335 \mathrm{bp}$ amplicon that is also detected by a 1.5\% agarose gel electrophoresis. Genotyping quality control was performed with all genotypes determined by two independent technicians with the results entered into the database in duplicate. Additionally, $10 \%$ of the samples were randomly reanalyzed.

\subsection{Statistical Methods}

The allele and genotype frequencies were estimated by counting. The agreement of genotype frequencies with the Hardy-Weinberg equilibrium expectations was tested using the chi-square test. The SPSS statistical program version 13 was used to compare categorical variables among groups and adjusted residuals. Comparisons of mean values of quantitative variables were carried out by independent t-tests and ANOVA by ranks with Tukey's post hoc test correction for multiple comparisons. Significance was considered at $\mathrm{P}<0.05$.

\section{Results}

Physical and anthropometric variables of the subjects are presented in Table 1. Age, weight, height, and BMI mean values did not differ significantly between the sedentary and physically active groups $(\mathrm{P}>0.05)$. Supine and sitting HR was higher in the sedentary group than in the physically active group $(\mathrm{P}=0.01)$, while SBP, and DBP did not differ between both groups ( $\mathrm{P}>0.05)$. Analysis of biochemical variables showed that total cholesterol, LDL cholesterol, and triglyceride levels in serum were higher in the sedentary group than in the physically active group $(\mathrm{P}<0.05)$. Other variables, such as fasting glucose, urea, creatinine, HDL cholesterol, progesterone, and estradiol were not statistically different between the sedentary and physically active groups $(\mathrm{P}>0.05)$.

\begin{tabular}{|c|c|c|c|}
\hline Variables & Sedentary $(n=58)$ & Physically Active $(n=59)$ & PValue $^{b}$ \\
\hline Age, $y$ & $23.7 \pm 4.5$ & $22.1 \pm 4.4$ & 0.07 \\
\hline Weight, kg & $59.5 \pm 7.0$ & $58.7 \pm 7.2$ & 0.52 \\
\hline Height, cm & $164.7 \pm 7.0$ & $165.5 \pm 6.7$ & 0.51 \\
\hline Body mass index, $\mathrm{kg} / \mathrm{m}^{2}$ & $21.9 \pm 2.0$ & $21.5 \pm 1.8$ & 0.24 \\
\hline Supine heart rate, bpm & $68.3 \pm 8.8$ & $64.3 \pm 9.9$ & 0.02 \\
\hline Sitting heart rate, bpm & $74.7 \pm 9.6$ & $69.6 \pm 10.4$ & 0.01 \\
\hline Systolic blood pressure, $\mathrm{mmHg}$ & $110.6 \pm 9.4$ & $110.4 \pm 7.8$ & 0.88 \\
\hline Diastolic blood pressure, $\mathrm{mmHg}$ & $71.6 \pm 7.9$ & $74 \pm 6.8$ & 0.09 \\
\hline Fasting glucose, $\mathrm{mg} / \mathrm{dL}$ & $72 \pm 7.0$ & $70 \pm 5.0$ & 0.88 \\
\hline Urea, mg/dL & $22 \pm 5.0$ & $24 \pm 4.0$ & 0.75 \\
\hline Creatinine, $\mathrm{mg} / \mathrm{dL}$ & $0.6 \pm 0.3$ & $0.7 \pm 0.3$ & 0.65 \\
\hline Total cholesterol, mg/dL & $161 \pm 29.0$ & $175 \pm 26.0$ & 0.03 \\
\hline Low-density lipoprotein cholesterol, mg/dL & $109 \pm 24.0$ & $75 \pm 23.0$ & 0.01 \\
\hline High-density lipoprotein cholesterol, mg/dL & $41 \pm 8.0$ & $53 \pm 16.0$ & 0.09 \\
\hline Triglycerides, mg/dL & $92 \pm 30.0$ & $77 \pm 15.0$ & 0.04 \\
\hline Progesterona, $\mathbf{n g} / \mathbf{m L}$ & $1.8 \pm 6.0$ & $1.6 \pm 5.0$ & 0.33 \\
\hline Estradiol, pg/mL & $102 \pm 57.0$ & $92 \pm 25.0$ & 0.21 \\
\hline
\end{tabular}

\footnotetext{
${ }^{\mathrm{a}}$ Data are presented as mean $\pm \mathrm{SD}$.

b Compared by independent t-test.
} 
Verlengia R et al.

Genotype distribution of ACE indel polymorphism was within the expectations of the Hardy-Weinberg equilibrium for both the physically active group (II $=0.413, \mathrm{P}=$ 0.5 ) and the sedentary state group (II $=0.004, \mathrm{P}=0.9$ ). The ACE indel genotype and allele frequencies did not differ between the physically active and the sedentary state groups ( $\mathrm{P}>0.05$; Table 2$)$.

\subsection{Aerobic Function Capacity During the Cardio- pulmonary Exercise Test}

Table 3 summarizes aerobic function data including the ventilatory response at the peak of the CPET, according to the genotypes of ACE indel polymorphism using co-dominant, dominant and recessive models of inheri- tance. $\mathrm{VO}_{2}$ peak, $\mathrm{VCO}_{2}$, VE, power output, $\mathrm{HR}$, SBP, and DBP mean values were not different among the ACE genotypes in the sedentary and active groups $(\mathrm{P}>0.05)$. There was also no relationship between cardiorespiratory variables during the test $(\mathrm{P}>0.05)$ using dominant (DD vs. D1 + II) or recessive (II vs. DD + DI) models of inheritance. These results therefore revealed that, independent of the ACE genotype carried, physically active women had higher $\mathrm{VO}_{2}$ peak, $\mathrm{VCO}_{2}$, VE, and power output mean values than the sedentary group had at the peak of the exercise test $(\mathrm{P}$ $<0.05$ ). Moreover, HR, SBP and DBP did not show significant differences $(\mathrm{P}>0.05)$ at the peak of the exercise test. The ACE indel polymorphism had no effect $(\mathrm{P}>0.05)$ on the variables $\mathrm{VO}_{2}$ peak, $\mathrm{VCO}_{2}$, VE, power output, $\mathrm{HR}, \mathrm{SBP}$, and DBP in the data from total sample (data not shown).

\begin{tabular}{|c|c|c|c|}
\hline & Active $(n=59)$ & Sedentary $(n=58)$ & PValue \\
\hline Genotypes & & & 0.2 \\
\hline DD & $17(28.8)$ & $21(36.2)$ & \\
\hline DI & $27(45.8)$ & $28(48.3)$ & \\
\hline II & $15(25.4)$ & $9(15.5)$ & \\
\hline Alleles & & & 0.2 \\
\hline D & $30(50.9)$ & $35(60.3)$ & \\
\hline I & $29(49.1)$ & $23(39.7)$ & \\
\hline
\end{tabular}

a Data are presented as No. (\%).

Table 3. Dependent Variables for Cardiorespiratory Responses in Physically Active and Sedentary (DD, DI, II Genotypes) Groups During the Cardiopulmonary Test $\mathrm{a}, \mathrm{b}, \mathrm{c}$

\begin{tabular}{|c|c|c|c|c|c|c|c|}
\hline & $\underset{\text { min }}{\mathrm{Vo}_{2}, \mathrm{~mL} / \mathrm{kg} /}$ & $\underset{\text { min }}{\mathrm{VO}_{2}, \mathrm{~mL} / \mathrm{kg} /}$ & $\begin{array}{c}\text { Ventilation, } \\
\text { L/min }\end{array}$ & Power, Watts & $\begin{array}{c}\text { Heart Rate, } \\
\text { bpm }\end{array}$ & SBP, mmHg & DBP, $\mathrm{mmHg}$ \\
\hline \multicolumn{8}{|c|}{$\begin{array}{l}\text { Physically } \\
\text { active }\end{array}$} \\
\hline DD & $31.0 \pm 3.9^{d}$ & $2.1 \pm 0.2^{d}$ & $60.6 \pm 9.8^{d}$ & $168.5 \pm 26.4^{d}$ & $180.1 \pm 9.2$ & $177.1 \pm 2.8$ & $79.3 \pm 5.5$ \\
\hline DI & $32.6 \pm 4.0^{\mathrm{e}}$ & $2.1 \pm 0.3^{\mathrm{e}}$ & $60.9 \pm 12.3^{\mathrm{e}}$ & $168.6 \pm 24.9^{\mathrm{e}}$ & $177.5 \pm 12.4$ & $179.5 \pm 2.4$ & $78.1 \pm 4.8$ \\
\hline II & $33.7 \pm 1.9^{f}$ & $2.3 \pm 0.3^{f}$ & $66.4 \pm 10.1^{\mathrm{f}}$ & $173.2 \pm 25.7^{\mathrm{f}}$ & $180.0 \pm 11.5$ & $178.0 \pm 1.5$ & $77.8 \pm 3.2$ \\
\hline \multicolumn{8}{|c|}{ PValue } \\
\hline C & 0.2 & 0.4 & 0.9 & 0.1 & 0.1 & 0.9 & 0.8 \\
\hline $\mathrm{D}$ & 0.9 & 0.1 & 0.7 & 0.3 & 0.3 & 0.2 & 0.8 \\
\hline $\mathrm{R}$ & 0.5 & 0.7 & 0.6 & 0.7 & 0.6 & 1 & 0.4 \\
\hline \multicolumn{8}{|c|}{ Sedentary } \\
\hline DD & $24.6 \pm 2.4$ & $1.7 \pm 0.2$ & $51.1 \pm 10.3$ & $132.9 \pm 18.1$ & $179.4 \pm 12.3$ & $179.5 \pm 1.4$ & $80.1 \pm 3.4$ \\
\hline DI & $23.9 \pm 3.1$ & $1.6 \pm 0.2$ & $50.3 \pm 12.3$ & $130.5 \pm 17.7$ & $175.4 \pm 9.8$ & $179.4 \pm 2.5$ & $82.6 \pm 2.7$ \\
\hline II & $29.2 \pm 5.9$ & $1.8 \pm 0.4$ & $51.4 \pm 15.7$ & $134.6 \pm 18.8$ & $177.8 \pm 20.2$ & $177.1 \pm 3.5$ & $79.0 \pm 3.3$ \\
\hline \multicolumn{8}{|c|}{ PValue $^{\mathrm{d}}$} \\
\hline $\mathrm{C}$ & 0.07 & 0.4 & 0.2 & 0.1 & 0.2 & 0.7 & 0.7 \\
\hline $\mathrm{D}$ & 0.08 & 0.7 & 0.6 & 0.2 & 0.7 & 0.5 & 0.5 \\
\hline $\mathrm{R}$ & 0.09 & 0.7 & 0.6 & 0.3 & 1 & 0.7 & 0.6 \\
\hline
\end{tabular}

${ }^{\mathrm{a}}$ Abbreviations: C, co-dominant model (DD vs. DI vs. II); D, dominant model (DD vs. DI + II); DBP, diastolic blood pressure; R, recessive model (II vs. DD

$+\mathrm{DI})$; $\mathrm{SBP}$, systolic blood pressure; $\mathrm{VO}_{2}$, oxygen uptake; $\mathrm{VCO}_{2}$, carbon dioxide output.

$\mathrm{b}$ Data are presented as mean $\pm \mathrm{SD}$.

${ }^{\mathrm{c}}$ Values were compared by ANOVA (co-dominant model) and independent t-test (dominant and recessive models).

$\mathrm{d}$ Significantly different from genotype DD sedentary group $(\mathrm{P}<0.05)$.

e Significantly different from genotype DI sedentary group $(\mathrm{P}<0.05)$.

$\mathrm{f}$ Significantly different from genotype II sedentary group $(\mathrm{P}<0.05)$. 
Verlengia R et al.

\section{Discussion}

In the present study, the sedentary group was classified as having low cardiorespiratory fitness according to the American Heart Association (30), and the physically active group was classified as having regular cardiorespiratory fitness. Additionally, total cholesterol, LDL cholesterol, and plasma triglycerides concentrations were significantly lower in the physically active group. These data reinforce the importance of physical activity for the maintenance of cardiorespiratory fitness and metabolic status (24). No significant difference was found in anthropometric variables, blood pressure, hormonal profiles, and renal function (creatinine, urea), which show the homogeneity of the sample. The main finding of this study was no association of ACE variant with $\mathrm{VO}_{2}$ peak, $\mathrm{VCO}_{2}$, VE and power output at the maximal CPET in the sample of healthy women, independent of the physical activity status. According to the population studied, our data show that the level of aerobic physical activity is associated with improvements in cardiorespiratory fitness. However, the improvements were not enough to show a positive interaction with the polymorphism, and were independent of the physical activity status in the population studied. The frequencies of the ACE D allele in the physically active group (51.7\%) and sedentary group (60.3\%) were similar to those previously reported in sample populations in North American (18), European (20), Australian (31), and Brazilian (32). The similarity of D allele frequencies between physically active and sedentary women is suggestive that this variant is not associated with the physical activity status in young women. Aerobic physical activity is responsible for several physiological adaptations in the cardiorespiratory system and skeletal muscle that lead to increased maximal aerobic power and endurance performance (33, 34). Likewise, Rankinen et al. evaluated a cohort of sedentary Caucasian families $(n=476)$ and sedentary Africans $(n=248)$ before and after 20 weeks of an aerobic training program performed on a cycle ergometer (21). The results demonstrated no effects of ACE indel polymorphism on $\mathrm{VO}_{2}$ max values before and after the physical training program. Day et al. also did not detect a significant association between the ACE indel polymorphism and $\mathrm{VO}_{2}$ max and the mechanical efficiency of muscle contractions during a cycle ergometry exercise test in sedentary women (20). Plasma ACE activity was also not related to the maximal aerobic power or mechanical efficiency (20). In accordance with Rankinen et al. (21) and Day et al. (20), our data demonstrated no sufficient influence of a single polymorphism (rs1799752) on the phenotype of cardiorespiratory performance of physically active and sedentary young women. This leads to the discussion concerning the analysis of interaction between two or more gene polymorphisms on human performance (35) or other regulatory mechanisms such as epigenetics (36). Alternatively, our data disagree with Hagberg et al. who evaluated the cardiorespiratory fitness in postmenopausal women (sedentary, physically active, and athlete groups) and observed that women carrying the II genotype had higher $\mathrm{VO}_{2}$ max values and estimated maximal arteriovenous $\mathrm{O}_{2}$ difference $\left(\mathrm{a}-\mathrm{vDo}_{2}\right)(18,19)$. This suggests an increase in regulation of peripheral vascular tone with increased capillary perfusion and red cell transit time when compared with DI and DD genotypes. However, there were no differences in the variables of maximal stroke volume and maximal cardiac output index.

The physiological mechanism by which ACE indel polymorphism may modulate cardiorespiratory fitness would be that carriers of the II genotype have low plasma ACE activity (28), reducing the conversion rate of angiotensin I to angiotensin 2 (a vasoconstrictor), and decreasing the degradation of vasodilators such as bradykinin (8). Against the evidence that the II genotype is associated with better cardiorespiratory fitness, Zhao et al. investigated the relationship of the ACE indel polymorphism in 67 young Chinese men (37). In this study he found that the $\mathrm{VO}_{2}$ max values were significantly higher for the DD genotype when compared to other genotypes (I/D and 2), contradicting previous studies (18, 19). These contradictory results must be explained due to the heterogeneity of genetic variants of the population involved in the studies and the aerobic training status. Thus, most studies that have found positive effects of ACE indel polymorphism on maximal aerobic power have typically been conducted in homogeneous ethnic populations and training status. This could overestimate the effect of a single polymorphism in physical performance, as observed in studies conducted with elite endurance athletes $(12,13,16)$.

In physically active women, the level of trainability was not large enough to promote significant cardiovascular and muscular adaptations, as observed by the $\mathrm{VO}_{2}$ peak values, when compared with studies that evaluated athletes $(38,39)$. Therefore, our data indicate that in sedentary or physically active women with low and moderate levels of trainability, a single ACE polymorphism does not significantly affect cardiorespiratory performance, since the central and peripheral factors are limiting the $\mathrm{VO}_{2}$ peak values in the maximal cardiopulmonary test (2).

Our study has some limitations that need to be addressed. Firstly, the small sample size studied (both physically active and sedentary Brazilian women) could never adequately represent the global population. Secondly, we did not evaluate systemic plasma ACE activity, a factor that could elucidate the relationship between ACE indel genotypes and cardiorespiratory response during a physical test. These results do not support the concept that the genetic variation at the ACE locus contributes to the cardiorespiratory responses at the peak of exercise test in physically active or sedentary healthy women. This indicates that other factors might mediate these responses, including the physical training level of the women. 


\section{Acknowledgements}

We are grateful to the subjects who dedicated a great deal of time to participate in this study. ES, RDCH and $\mathrm{MHH}$ are recipients of fellowships from CNPq.

\section{Authors' Contributions}

Concept/Design: Rozangela Verlengia, Mario H. Hirata, Rosario D. Crespo Hirata, Ester Silva. Acquisition of Data: Ana C. Rebelo, Vandeni C. Kunz, Marco A. dos Santos Carneiro Cordeiro. Data Analysis/Interpretation: Rozangela Verlengia, Ana C. Rebelo, Alex H. Crisp. Critical Revision of the Manuscript: Mario H. Hirata, Ester Silva. Funds Collection: Ester Silva. Approval of the Article: Rozangela Verlengia, Ana C. Rebelo, Alex H. Crisp, Mario H. Hirata, Rosario D. Crespo Hirata, Ester Silva.

\section{Funding/Support}

This study was supported by grants from Conselho Nacional de Desenvolvimento Cientifico e Tecnologico (CNPq 370448/2007-3) and Fundacao de Amparo a Pesquisa do Estado de Sao Paulo (FAPESP 2006/56788-1).

\section{References}

1. Wasserman K, Hansen JE, Sue D. Principles of exercise testing and interpretation. 3 edPhiladelphia; 1999.

2. Bassett DR Jr, Howley ET. Limiting factors for maximum oxygen uptake and determinants of endurance performance. $\mathrm{Med} \mathrm{Sci}$ Sports Exerc. 2000;32(1):70-84.

3. Bouchard C. Genomic predictors of trainability. Exp Physiol. 2012;97(3):347-52.

4. White RD, Evans $\mathrm{CH}$. Performing the exercise test. Prim. Care. 2001;28(1):29-53.

5. Ferrazza AM, Martolini D, Valli G, Palange P. Cardiopulmonary exercise testing in the functional and prognostic evaluation of patients with pulmonary diseases. Respiration. 2009;77(1):3-17.

6. Domingo R, Sturrock ED, Collins M. ACE activity and endurance performance during the South African Ironman triathlons. Int I Sports Med. 2013;34(5):402-8.

7. Jones A, Montgomery HE, Woods DR. Human performance: a role for the ACE genotype? Exerc Sport Sci Rev. 2002;30(4):184-90.

8. Woods DR, Humphries SE. The ACE I/D Polymorphism and Human Physical Performance. Trends Endocrinol metabol. 2000;11(10):416-20.

9. Puthucheary Z, Skipworth JR, Rawal J, Loosemore M, Van Someren K, Montgomery HE. The ACE gene and human performance: 12 years on. Sports Med. 2011;41(6):433-48.

10. Gayagay G, Yu B, Hambly B, Boston T, Hahn A, Celermajer DS, et al. Elite endurance athletes and the ACE I allele - the role of genes in athletic performance. Hum Genet.1998;103(1):48-50.

11. Cieszczyk P, Krupecki K, Maciejewska A, Sawczuk M. The angiotensin converting enzyme gene I/D polymorphism in Polish rowers. Int J Sports Med. 2009;30(8):624-7.

12. Myerson S, Hemingway H, Budget R, Martin J, Humphries S, Montgomery H. Human angiotensin I-converting enzyme gene and endurance performance. J Appl Physiol (1985). 1999;87(4):1313-6.

13. Tsianos G, Sanders J, Dhamrait S, Humphries S, Grant S, Montgomery $\mathrm{H}$. The ACE gene insertion/deletion polymorphism and elite endurance swimming. Eur J Appl Physiol. 2004;92(3):360-2.

14. Collins M, Xenophontos SL, Cariolou MA, Mokone GG, Hudson DE, Anastasiades L, et al. The ACE gene and endurance performance during the South African Ironman Triathlons. Med Sci Sports Exerc. 2004;36(8):1314-20.
15. Tsianos G, Eleftheriou KI, Hawe E, Woolrich L, Watt M, Watt I, et al. Performance at altitude and angiotensin I-converting enzyme genotype. Eur J Appl Physiol. 2005;93(5-6):630-3.

16. Thompson J, Raitt J, Hutchings L, Drenos F, Bjargo E, Loset A, et al. Angiotensin-converting enzyme genotype and successful ascent to extreme high altitude. High Alt Med Biol. 2007;8(4):278-85.

17. Bouchard C, Daw EW, Rice T, Perusse L, Gagnon J, Province MA, et al. Familial resemblance for VO2max in the sedentary state: the HERITAGE family study. Med Sci Sports Exerc. 1998;30(2):252-8.

18. Hagberg JM, Ferrell RE, McCole SD, Wilund KR, Moore GE. VO2 max is associated with ACE genotype in postmenopausal women. J Appl Physiol (1985). 1998;85(5):1842-6.

19. Hagberg JM, McCole SD, Brown MD, Ferrell RE, Wilund KR, Huberty A, et al. ACE insertion/deletion polymorphism and submaximal exercise hemodynamics in postmenopausal women. $J$ Appl Physiol (1985). 2002;92(3):1083-8.

20. Day SH, Gohlke P, Dhamrait SS, Williams AG. No correlation between circulating ACE activity and VO2max or mechanical efficiency in women. Eur J Appl Physiol. 2007;99(1):11-8.

21. Rankinen T, Perusse L, Gagnon J, Chagnon YC, Leon AS, Skinner JS, et al. Angiotensin-converting enzyme ID polymorphism and fitness phenotype in the HERITAGE Family Study. J Appl Physiol (1985). 2000;88(3):1029-35.

22. Woods DR, World M, Rayson MP, Williams AG, Jubb M, Jamshidi $\mathrm{Y}$, et al. Endurance enhancement related to the human angiotensin I-converting enzyme I-D polymorphism is not due to differences in the cardiorespiratory response to training. Eur J App Physiol. 2002;86(3):240-4.

23. Roltsch MH, Brown MD, Hand BD, Kostek MC, Phares DA, Huberty A, et al. No association between ACE I/D polymorphism and cardiovascular hemodynamics during exercise in young women. Int J Sports Med. 2005;26(8):638-44.

24. American College of Sports Medicine Position Stand. The recom mended quantity and quality of exercise for developing and maintaining cardiorespiratory and muscular fitness, and flexibility in healthy adults. Med Sci Sports Exerc. 1998;30(6):975-91.

25. Friedewald WT, Levy RI, Fredrickson DS. Estimation of the con centration of low-density lipoprotein cholesterol in plasma, without use of the preparative ultracentrifuge. Clin Chem. 1972;18(6):499-502.

26. British Association of Sports Sciences London, Hale T, British Association of Sports Sciences, Sports Physiology Section. Position Statement on the Physiological Assessment of the Elite Competitor 2nd ed: British Association of Sports Sciences; 1988.

27. Salazar LA, Hirata MH, Cavalli SA, Machado MO, Hirata RD. Optimized procedure for DNA isolation from fresh and cryopreserved clotted human blood useful in clinical molecular testing. Clin Chem. 1998;44(8 Pt1):1748-50.

28. Rigat B, Hubert C, Alhenc-Gelas F, Cambien F, Corvol P, Soubrier F. An insertion/deletion polymorphism in the angiotensin I-converting enzyme gene accounting for half the variance of serum enzyme levels.J Clin Invest. 1990;86(4):1343-6.

29. Lindpaintner K, Pfeffer MA. Molecular genetics crying wolf? The case of the angiotensin-converting enzyme gene and cardiovascular disease. Am J Cardiol.1995;25(7):1632-3.

30. American Heart Association, Committee on Exercise. Exercise testing and training of apparently healthy individuals: a handbook for physicians. American Heart Assoc; 1972.

31. Taylor RR, Mamotte CD, Fallon K, van Bockxmeer FM. Elite ath letes and the gene for angiotensin-converting enzyme. J Appl Physiol (1985). 1999;87(3):1035-7.

32. Inacio J, Goulart Filho LR, Vieira GS. Frequencias genotipicas e alelicas do gene do polimorfismo da ECA I/D na populacao brasileira. Bio Sci J. 2006;20(1).

33. Jones AM, Carter H. The Effect of Endurance Training on Parameters of Aerobic Fitness. Sport Medic. 2000;29(6):373-86.

34. Coffey VG, Hawley JA. The Molecular Bases of Training Adaptation. Sport Medic J. 2007;37(9):737-63.

35. Davids K, Baker J. Genes, Environment and Sport Performance. 
Verlengia R et al.

Sport Medic J. 2007;37(11):961-80.

36. Raleigh SM. Last Word on Viewpoint: Epigenetic regulation of the ACE gene might be more relevant to endurance physiology than the I/D polymorphism. J Appl. 2012;112(6):1086.

37. Zhao B, Moochhala SM, Tham S, Lu J, Chia M, Byrne C, et al. Relationship between angiotensin-converting enzyme ID polymorphism and VO2max of Chinese males. Life Sci. 2003; 73(20):2625-30.
38. Goh KP, Chew K, Koh A, Guan M, Wong YS, Sum CF. The relationship between ACE gene ID polymorphism and aerobic capacity in Asian rugby players. Singapore Med J. 2009;50(10):997-1003.

39. Boraita A, de la Rosa A, Heras ME, de la Torre AI, Canda A, Rabadan $\mathrm{M}$, et al. Cardiovascular adaptation, functional capacity and Angiotensin-converting enzyme I/D polymorphism in elite athletes. Rev Esp Cardiol. 2010;63(7):810-9. 